\title{
Genetics and molecular pathogenesis of sporadic and hereditary cerebral amyloid angiopathies
}

\author{
Tamas Revesz • Janice L. Holton · Tammaryn Lashley • \\ Gordon Plant · Blas Frangione · Agueda Rostagno · \\ Jorge Ghiso
}

Published online: 10 June 2009

(c) Springer-Verlag 2009

\section{Erratum to: Acta Neuropathol (2009) 118:115-130 \\ DOI 10.1007/s00401-009-0501-8}

The authors of the manuscript, "Genetics and molecular pathogenesis of sporadic and hereditary cerebral amyloid angiopathies", Acta Neuropathol 118:115-130, 2009, regret the omission of the following acknowledgements.

The Queen Square Brain Bank is supported by the Reta Lila Weston Institute for Neurological Studies and the
Progressive Supranuclear Palsy (Europe) Association. TR and JLH are recipients of grants from the Sarah Matheson Trust for Multiple System Atrophy, the Alzheimer's Research Trust and Brain Net Europe (FP6: BNEII No LSHM-CT-2004-503039). This work was also supported in part by NIH grants NS051715 and AG10491, the American Heart Association, and the Alzheimer's Association, USA.

The online version of the original article can be found under doi:10.1007/s00401-009-0501-8.

T. Revesz $(\bowtie) \cdot$ J. L. Holton · T. Lashley

Queen Square Brain Bank for Neurological Disorders,

Department of Molecular Neuroscience,

UCL Institute of Neurology, University College London,

Queen Square, London WC1N 3BG, UK

e-mail: t.revesz@ion.ucl.ac.uk

G. Plant

The National Hospital for Neurology and Neurosurgery,

UCLH NHS Foundation Trust, Queen Square, London, UK

B. Frangione $\cdot$ A. Rostagno $\cdot$ J. Ghiso

Department of Pathology,

New York University School of Medicine,

New York, USA

B. Frangione $\cdot$ J. Ghiso

Department of Psychiatry,

New York University School of Medicine,

New York, USA 